\title{
APPLICABILITY OF NOTCH STRESS-STRAIN CORRECTION METHODS TO LOW-CYCLE FATIGUE LIFE PREDICTION OF TURBINE ROTORS SUBJECTED TO THERMOMECHANICAL LOADS
}

\author{
Mariusz BANASZKIEWICZ*, Waldemar DUDDA* \\ *Energy Conversion Department, The Szewalski Institute of Fluid-Flow Machinery,
Polish Academy of Sciences, Fiszera 14, 80-231 Gdańsk, Poland
${ }^{*}$ Faculty of Technical Sciences, Department of Mechanics and Machine Design,
University of Warmia and Mazury, Oczapowskiego 2, 10-719 Olsztyn, Poland \\ mbanaszkiewicz@imp.gda.pl, dudda@uwm.edu.pl
}

received 5 April 2017, revised 23 July 2018, accepted 26 July 2018

\begin{abstract}
The paper analyses the possibility of using analytical methods of notch stress-strain correction in low-cycle fatigue life predictions of steam turbine rotors operating under non-isothermal conditions. The assessment was performed by comparing strain amplitudes calculated using the Neuber and Glinka-Molski methods and those predicted by the finite element analysis (FEA) employing elastic-plastic material model. The results of investigations reveal that the Neuber method provides an upper bound limit, while the GlinkaMolski method results in a lower bound limit of strain amplitude. In the case of rotor heat grooves, both methods provide equally accurate results of notch strain amplitude and are suited to estimating lower and upper bound limits of low-cycle fatigue life under non-isothermal conditions.
\end{abstract}

Key words: Low-Cycle Fatigue, Turbine Rotors, Thermomechanical Load

\section{INTRODUCTION}

Steam turbine rotors operating at high temperature are subject to creep and/or fatigue damage which leads to crack initiation and propagation during long-term operation (Viswanathan, 1989). When a crack reaches a critical size, its uncontrolled propagation may lead to catastrophic failure, and that is why cracking in rotating components should be avoided for safety reasons.

Fatigue crack initiation in steam turbine rotors can occur after less than 1000 cycles (Banaszkiewicz, 2018) and is caused by high thermal stresses induced by temperature gradients developed during transient operating conditions like start-ups, shutdowns or load changes. The stresses may exceed the proof stress of material at the regions of stress concentration resulting in development of local plastic deformation.

Steam turbines of large power output are of multi-cylinder design and typically consist of high pressure (HP), intermediate pressure (IP) and low pressure (LP) cylinders (Fig. 1). The HP and IP modules are fed with live and reheat steam, respectively, which has high nominal temperature changing during the turbine start-up from initial to rated values. Temperature changes are accompanied by steam pressure and mass flow rate variations giving rise to non-stationary thermal loading of steam turbine components. These high thermal loads in conjunction with large component dimensions (i.e. diameters and wall thicknesses) generate non-uniform temperature fields with high thermal gradients. Cyclic generation of thermal stresses occuring during startups and shutdowns may lead to crack initiation in thick-walled elements like rotors, casings or valve chests due to thermal fatigue.

Thermal fatigue cracking of steam turbine components is not the only technical problem related with turbine operation. Various thermal and mechanical inertia effects influence the operational characteristics of steam turbines and require dynamic models for accurate predictions of transient states (Celins et al., 2017). Differences in thermal expansion between rotors and casings result in altered axial clearances and their unsafe decrease during turbine operation must be avoided (Kosman et al., 2009). Mechanical contact between rotating and stationary elements occuring due to loss of clearance may lead to excessive vibration and material damage. Also rotor and blade vibrations affect turbine reliable operation and are subject to detailed analysis at the design phase and to online monitoring during turbine operation (Koneko et al., 2017). Rotordynamic analyses are performed at a very early stage of turbine design in order to avoid unsafe rotor resonances at various operating conditions. Dynamic excitations due to steam flow and rotor rotation are present in the steam path and adversly affect the turbine blading life.

There are specific areas on steam turbine rotors which are particularly susceptible to thermal fatigue cracking. These areas are characterized by geometrical irregularities, like grooves or transition radii and are subject to steam of high and quickly changing temperature. Locations where thermal fatigue cracks in impulse rotors were found are schematically shown in Fig. 2.

Transient temperature and stress distribution in turbine rotors can be accurately determined with the help of finite element models. Such models are routinely used in design calculations where typical operating conditions are simulated. However, such an approach becomes unsuitable for online calculations or analysis of long-term service conditions, and analytical methods for stressstrain correction are used for such purposes (Banaszkiewicz, 2015; 2016; 2018; Ince and Glinka, 2013; 2016; Ince at al., 2014).

The Neuber rule (Neuber, 1961) and Glinka-Molski method (Molski and Glinka, 1981) are the most commonly used ap- 
proaches in analysing elastic-plastic strains and stresses at notch tip. The methods have been employed for calculating stress-strain histories and fatigue life of components subjected to multiaxial loading (Buczyński and Glinka, 1997; 2001; Ince, 2016, 2017; Ince and Bang, 2017; Moftakhar et al., 1995). In all cases, the loading was non-proportional and applied at constant temperature. The Neuber rule has also been used to determine stress- strain evolution in a notched specimen at non-isothermal conditions (Gordon et al., 2008) and to compute thermal stresses in turbine casings (Gehlot et al., 2012). Both analytical methods have also been applied to predict fatigue crack initiation life in high strength structural steel welded joints based on local stress and strain ranges (Tricoteaux et al., 2007).

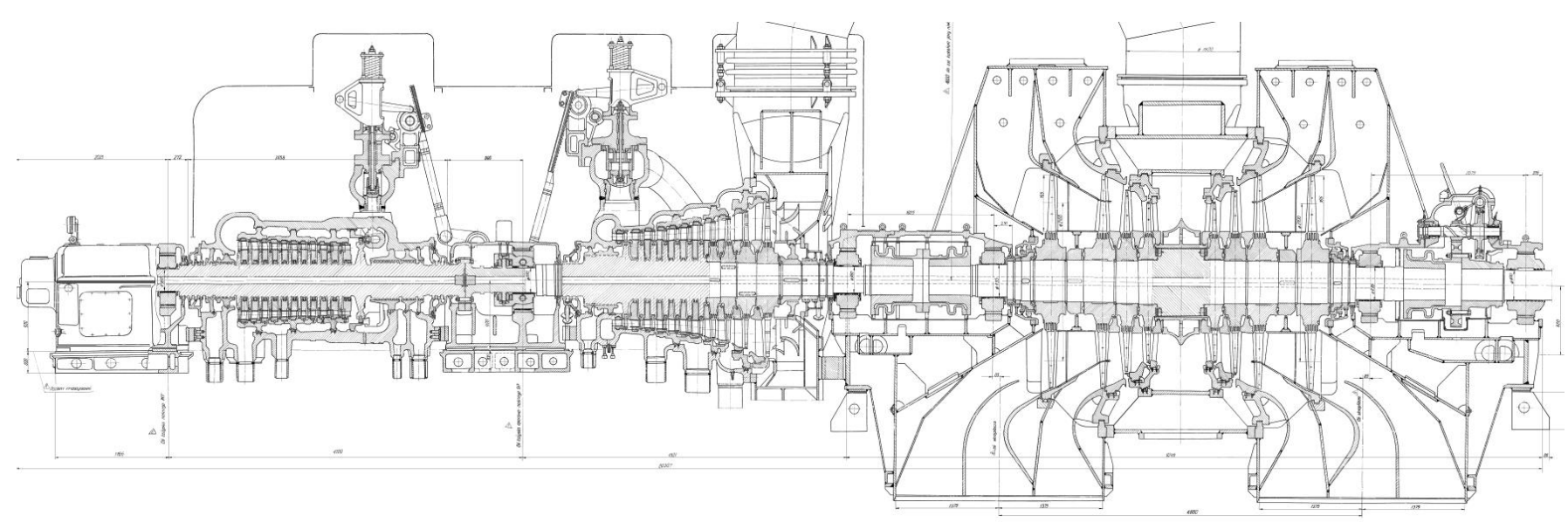

Fig. 1. Longitudinal section of large power output steam turbine

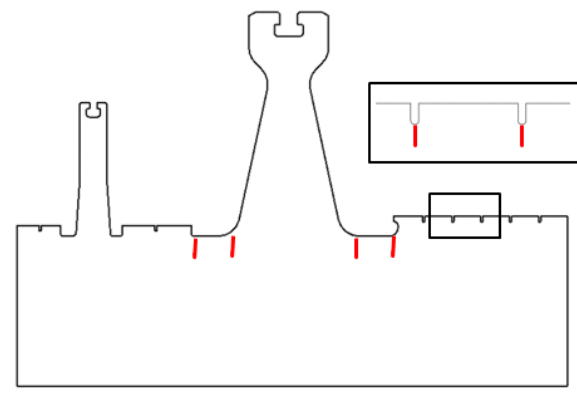

Fig. 2. Typical location of fatigue cracking in impulse rotors

It is commonly known that in most cases Glinka-Molski method underestimates the notch tip stresses and strains, while the Neuber rule tends to overestimate the notch stress/strain (Shin et al., 1994). However, predictions of both methods are similar for the distributions of stress and strain ahead of a notch tip where both fields are considerably underestimated by analytical methods (Guo et al., 1998).

This paper analyses the use of these methods to determining elastic-plastic strain amplitudes which are required in low-cycle fatigue analysis under thermomechanical loading conditions. Numerical calculations are performed for U-shape circumferential grooves used in steam turbine rotors which are known to be prone to fatigue cracking originating from the bottom surfaces of the grooves.

\section{NOTCH STRESS-STRAIN CORRECTION METHODS}

Thermoelastic notch stresses in the areas of fatigue cracking exceed the material yield stress and consideration of elasticplastic material response is crucial for proper estimation of fatigue life. The most commonly used methods for elastic-plastic stressstrain correction basing on the elastic solution are Neuber's rule and Glinka-Molski equivalent strain energy density method. In case of multi-axial state of stress and strain, extended Neuber rule is used (Hoffmann and Seeger, 1985):

$\sigma_{e q} \varepsilon_{e q}=\sigma_{e q}^{e} \varepsilon_{e q}^{e}$

where: $\sigma_{e q}$ - equivalent stress, $\varepsilon_{\mathrm{eq}}$ - equivalent strain, $\sigma_{e q}^{e}$ - equivalent stress obtained from elastic solution, $\varepsilon_{e q}^{e}-$ equivalent strain obtained from elastic solution. The equivalent strains are defined using mechnical strain components.

Similarly, Glinka-Molski method was extended for multi-axial state of stress using the definition of strain energy density (Moftakhar et al., 1995):

$\frac{1}{2} \sigma_{e q}^{e} \varepsilon_{e q}^{e}=\int_{0}^{\varepsilon_{e q}} \sigma_{e q} d \varepsilon_{e q}$

Graphical interpretation of both methods for elastic-linear strain hardening material is given in Fig. 3 and 4. Neuber rule (Fig. 3 ) assumes the equality of the total strain energy density at the notch tip in elastic (grey area under $\sigma_{e q}^{e}-A-\varepsilon_{e q}^{e}$ curve) and elastic-plastic state (shaded area under $\sigma_{e q}-B-\varepsilon_{e q}$ curve). The total strain energy density is defined as the sum of the strain energy density and the complementary strain energy density.

Glinka-Molski method (Fig. 4) assumes the equality between the strain energy density at the notch tip of a linear elastic body (grey area under elastic curve under $\sigma_{e q}^{e}-\varepsilon_{e q}^{e}$ ) and the strain energy density at the notch tip of a geometrically identical elasticplastic body (grey area under elastic-plastic stress-strain curve $\sigma_{e q}-\varepsilon_{e q}$ ) subjected to the same load.

The formulations of Neuber's rule and Glinka-Molski's method given by equation (1) and (2) are based on the equivalent stress and strain, and neglect the contribution of dilatation energy representing the influence of mean stress.

The equivalent stress $\sigma_{e q}$ is expressed by the deviatoric stress components $s_{i j}$ (Bednarski, 1995): 
$\sigma_{e q}=\sqrt{3 / 2 s_{i j} s_{i j}}$

and the equivalent strain $\varepsilon_{e q}$ is defined by the deviatoric strain components $\mathrm{e}_{\mathrm{ij}}$ with energy conjugate strain definition:

$\varepsilon_{e q}=\sqrt{2 / 3 e_{i j} e_{i j}}$

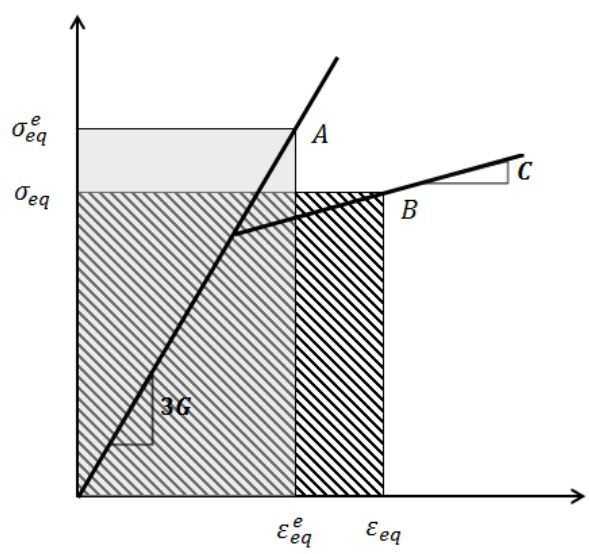

Fig. 3. Graphical interpretation of the Neuber rule

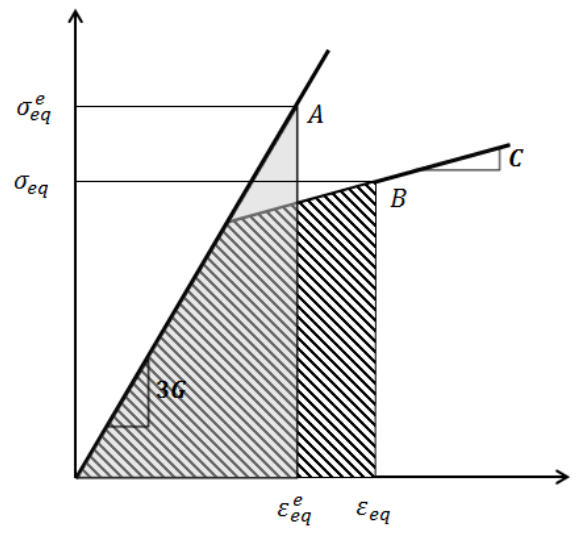

Fig. 4. Graphical interpretation of the Glinka-Molski method

For proportional loading conditions and multiaxial state of stress, the equivalent strain can be expressed as a sum of equivalent elastic strain $\varepsilon_{e q}^{e}$ and equivalent plastic strain $\varepsilon_{e q}^{p}$ (Harkegard and Mann, 2003)

$\varepsilon_{e q}=\varepsilon_{e q}^{e}+\varepsilon_{e q}^{p}$

The equivalent elastic strain is defined as

$\varepsilon_{e q}^{e}=\sigma_{e q} / 3 G$

where $G$ is shear modulus, and the equivalent plastic strain in linear kinematic model can be expressed as

$\varepsilon_{e q}^{p}=\left(\sigma_{e q}-\sigma_{y}\right) / C$

where $\sigma_{y}$ is material proof stress, and $C$ is a kinematic hardening parameter.

For cyclic stress-strain analysis, equations (1) and (2) are rewritten for the corresponding stress and strain amplitudes (Zeng and Fatemi, 2001, Banaszkiewicz, 2015)

$\sigma_{e q, a} \varepsilon_{e q, a}=\sigma_{e q, a}^{e} \varepsilon_{e q, a}^{e}$ $\frac{1}{2} \sigma_{e q, a}^{e} \varepsilon_{e q, a}^{e}=\int_{0}^{\varepsilon_{e q, a}} \sigma_{e q, a} d \varepsilon_{e q, a}$

The above two equations were used to determine elastoplastic strain amplitudes at the notch tip based on the stress and strain histories obtained from elastic material response.

\section{ELASTIC-PLASTIC MATERIAL MODEL}

Constitutive material behaviour can be described using various incremental plasticity models (Armstrong and Frederick, 1966; Chaboche, 1986; Garud, 1981; Mróz, 1967). Practical application of these cyclic plasticity models is often difficult due to significant number of material constants which have to be determined from cyclic tests.

For numerical calculations performed using a finite element method, simple plasticity model with the Prager-Ziegler linear kinematic hardening was adopted. The plasticity surface is defined by the Huber-Mises yield criterion

$F=f\left(\sigma_{i j}-\alpha_{i j}\right)-\sigma_{y}=0$

where $f\left(\sigma_{i j}-\alpha_{i j}\right)$ is the equivalent stress related to the backstress $\alpha_{\mathrm{ij}}$ defining translation of the yield surface. The yield function is traditionally defined by the formula

$f\left(\sigma_{i j}-\alpha_{i j}\right)=\sqrt{3 / 2\left(s_{i j}-\alpha_{i j}^{d}\right)\left(s_{i j}-\alpha_{i j}^{d}\right)}$

where $s_{i j}$ is a deviatoric part of the stress tensor $\sigma_{i j}$, while $\alpha_{i j}^{d}$ is a deviatoric part of the backstress tensor $\alpha_{i j}$.

The linear kinematic hardening model assumes the associated plastic flow rule given by the following formula:

$\dot{\varepsilon}_{i j}^{p}=\dot{\lambda} \frac{\partial F}{\partial \sigma_{i j}}=\dot{\lambda}\left(s_{i j}-\alpha_{i j}^{d}\right)$

where $\dot{\varepsilon}_{i j}^{p}$ denotes a plastic flow rate and $\dot{\lambda}$ stands for a plastic work. The rate of the backstress tensor is described by Ziegler's linear hardening law

$\dot{\alpha_{\imath \jmath}}=\dot{\mu}\left(\sigma_{i j}-\alpha_{i j}\right)$

where $\mu$ is a positive scalar coefficient.

\section{FINITE ELEMENT ANALYSIS OF TURBINE ROTOR}

A steam turbine rotor was adopted for evaluation of both analytical methods of the notch tip stresses-strain correction. Thermal boundary conditions were prepared for design start-up diagrams from a cold (CS), warm (WS) and hot start (HS), as well as for shutdown (SD). Transient thermal analyses were then carried out in order to determine instantaneous temperature distributions in the rotor during the mentioned above start-ups and shutdown. Fig. 5 presents an example of temperature distribution at an early phase of the cold start. The resulting thermomechanical stresses including stress components due to mechanical loading are shown in Fig. 6. As shown in the red box, thermoelastic stresses are concentrated at the tip of circumferential heat grooves. It results from significant temperature gradients in the radial direction and stress concentration due to geometrical notch. The elastic stresses are different in each groove, even though they have exactly the same geometry (the same notch factor). 


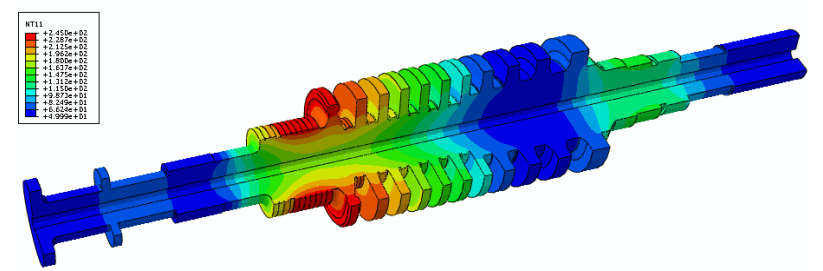

Fig. 5. Rotor temperature distribution at early phase of cold start

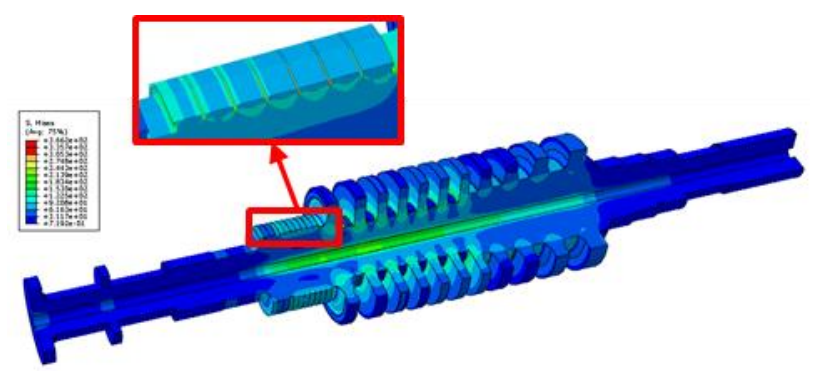

Fig. 6. Rotor equivalent stress distribution at early phase of cold start

Fig. 7 presents an example of temperature and stress variation in groove G1 and G3 during cold start-up. Temperature in both grooves increases at almost the same rate, but the equivalent Huber-Mises stress in groove G3 is much higher than the stress in groove $\mathrm{G} 1$. Detailed analysis of variation of the deviatoric stress components in the rotor heat grooves (Banaszkiewicz, 2018) has shown that the deviatoric stresses remain in nearly fixed proportions during the analysed start-stop cycles and consequently the loading can be assumed proportional. In such a case, stress/strain analyses can be performed using Hencky's equations.

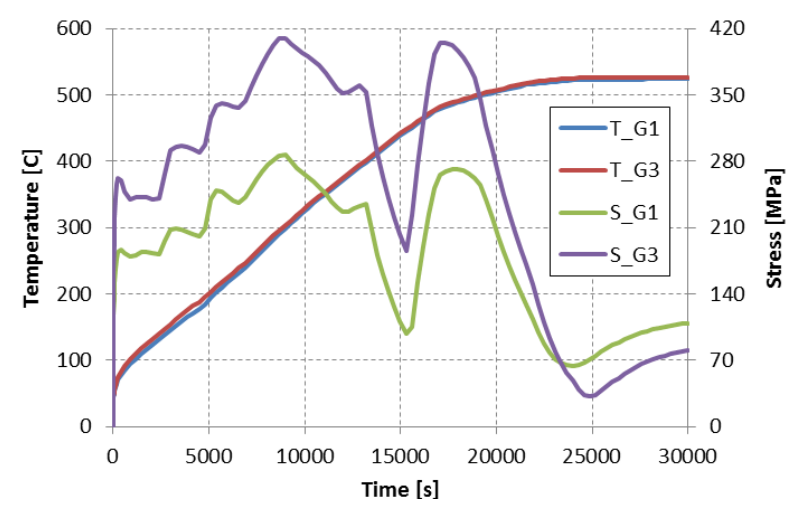

Fig. 7. Temperature and stress variations in groove $\mathrm{G} 1$ and $\mathrm{G} 3$ during cold start

In stress-life or strain-life approaches, both the stress/strain amplitude and ratio are required for determining the number of cycles to cracking. The stress ratios were calculated for the two non-zero stress components in the grooves using the stresses obtained in elastic and elastic-plastic analyses. As an example, Table 1 presents the stress ratios obtained for heat groove 4 . It is clearly seen that in all cases, the axial and circumferential stress ratios both in elastic and elastic-plastic condition are lower than minus 1. The elastic material model results in higher ratios and they assume higher values for the circumferential stress component. The low-cycle fatigue life assessment of the heat grooves can thus be safely performed using the strain life approach and fatigue data with zero mean stress $(R=-1)$ which are usually easily available for typical rotor materials.

Tab. 1. Stress ratios in heat groove 4 for different start-stop cycles

\begin{tabular}{|c|c|c|c|c|}
\hline \multirow[b]{2}{*}{$\begin{array}{l}\text { Cycle } \\
\text { type }\end{array}$} & \multicolumn{4}{|c|}{ Stress ratio [-] } \\
\hline & $\begin{array}{l}\text { Axial } \\
\text { elastic }\end{array}$ & $\begin{array}{l}\text { Axial } \\
\text { elastic- } \\
\text { plastic }\end{array}$ & $\begin{array}{l}\text { Circumferential } \\
\text { elastic }\end{array}$ & $\begin{array}{l}\text { Circumferential } \\
\text { elastic-plastic }\end{array}$ \\
\hline Cold & -1.29 & -1.22 & -1.58 & -1.26 \\
\hline Warm & -1.62 & -1.21 & -2.02 & -1.35 \\
\hline Hot & -1.58 & -1.01 & -2.05 & -1.18 \\
\hline
\end{tabular}

During transient operating conditions, plastic deformation occurs at the bottom of heat grooves as it is shown in Fig. 8 for groove 1 and 4 . The size of the plastic deformation zone is very small and the maximum plastic strains occur at the bottom of the groove nearly at its plane of symmetry. At this area thermoelastic stresses attain maximum values. The size of the plastic zone is different in all grooves due to different stresses and temperatures, but its shape is similar.
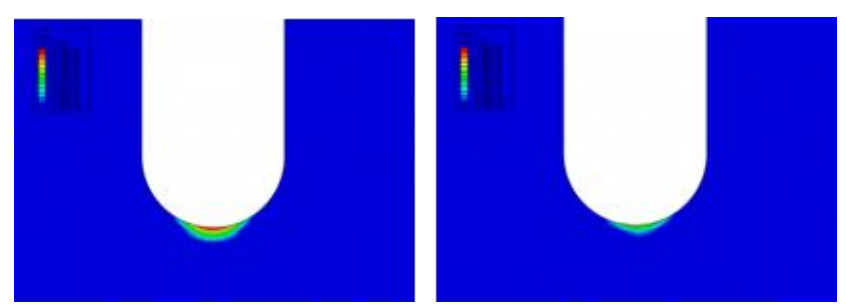

Fig. 8. Equivalent plastic strain distribution in heat groove 1 (left) and 3 (right) after 3 rd hot start cycle

\section{NOTCH STRAIN AMPLITUDE CORRECTION}

The analytical methods of stress-strain correction assume the equivalence of strain energy density in the actual elastic-plastic body and in geometrically identical pseudo-elastic body (Moftakhar et al., 1995). The methods are based on the assumption, that in the case of small-scale plastic yielding near the notch tip, the plastic zone is controlled by the surrounding elastic stress field and the energy density distribution in the plastic zone is almost the same as that in a linear elastic material (Zeng and Fatemi, 2001). This assumption enables to relate the notch tip strains and stresses in pseudo-elastic and elastic-plastic conditions. The Neuber rule represents the equality of the total strain energy (the strain energy and the complimentary strain energy density) at the notch tip, while the Glinka-Molski method considers only the strain energy density.

Before applying the approximate methods of notch tip stress and strain evaluation, the behaviour of strain energy densities during thermal cycling was investigated in order to check their equivalence in pseudo-elastic and elastic-plastic state. The total strain energy density variations in groove 3 during the cold start cycle are shown in Fig. 9. The curves representing pseudo-elastic and elastic-plastic energy coincide until first yielding occurs and then start to diverge. Most of the time, the elastic energy exceeds the elastic-plastic one, which is also the case at the extremum points of the energy curves. The difference between the energies 
is generally at the level of several percent. Similar behaviour was found for all the remaining grooves and other types of starts, confirming that this is a characteristic feature of this rotor.

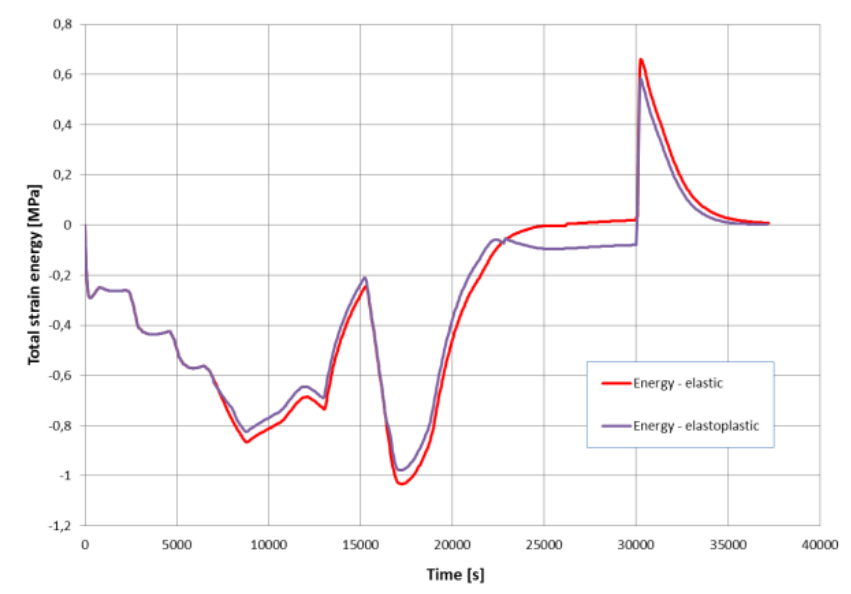

Fig. 9. Total strain energy variation in groove 3 during cold start

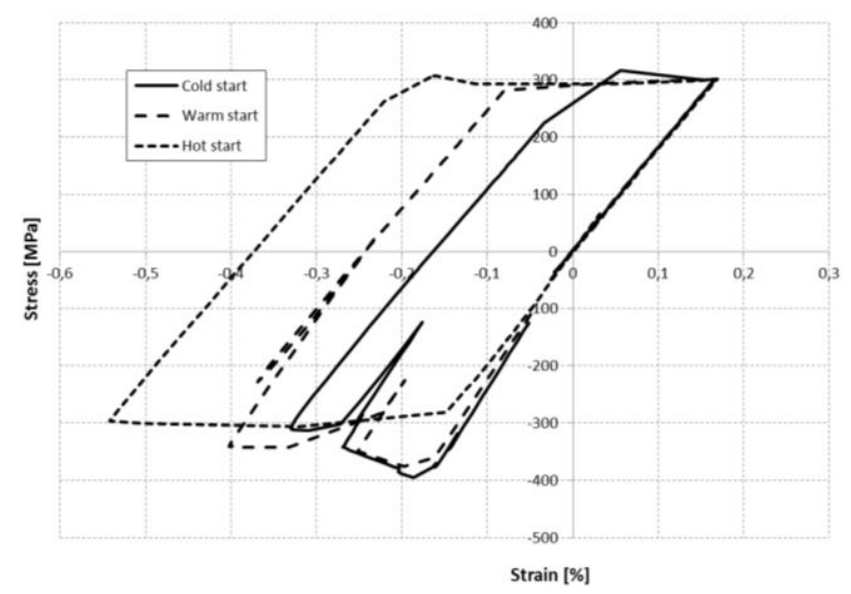

Fig. 10. Stress-strain hysteresis loops obtained from elastic-plastic analysis of the cold, warm and hot start

Strain amplitudes were determined from the stabilized stressstrain hysteresis loops calculated using the elastic-plastic material model. Fig. 10 presents the hysteresis loops obtained for the complete cycles including cold, warm and hot start-up and the subsequent shutdown phase. The calculated strain range is different for each start-stop cycle and the differences result form the start-up sections (compressive stress) of the curves. The shutdown stress is positive (tensile stress) and assumes the same value for different cycles.

Equations (8) and (9) can be transformed to quadratic equations using the strain definitions $(5) \div(7)$ under the assumption of linearly kinematic hardening material and proportional loading conditions (Lemaitre and Desmorat, 2005):

- for Neuber rule:

$C \varepsilon_{e q, a}^{2}+\left(\sigma_{y}-C \sigma_{y} / 3 G\right) \varepsilon_{e q, a}-\left(\sigma_{e q, a}^{e}\right)^{2} / 3 G=0$

- for Glinka-Molski method:

$C \varepsilon_{e q, a}^{2}+\left(2 \sigma_{y}-2 C \sigma_{y} / 3 G\right) \varepsilon_{e q, a}+$

$\left[C\left(\sigma_{y}\right)^{2}-3 G\left(\sigma_{e q, a}^{e}\right)^{2}-3 G\left(\sigma_{y}\right)^{2}\right] / 9 G^{2}=0$

The above two equations can be solved analytically by means of the discriminant method to obtain the strain amplitudes in the elastic-plastic state $\varepsilon_{e q, a}$. The existence of analytical solutions for strain amplitude is very important from the perspective of practical application to fatigue life analysis. Analytical expression for the strain amplitude can be used in lifetime calculations when a large number of cycles is to be analysed or for online monitoring of fatigue damage.

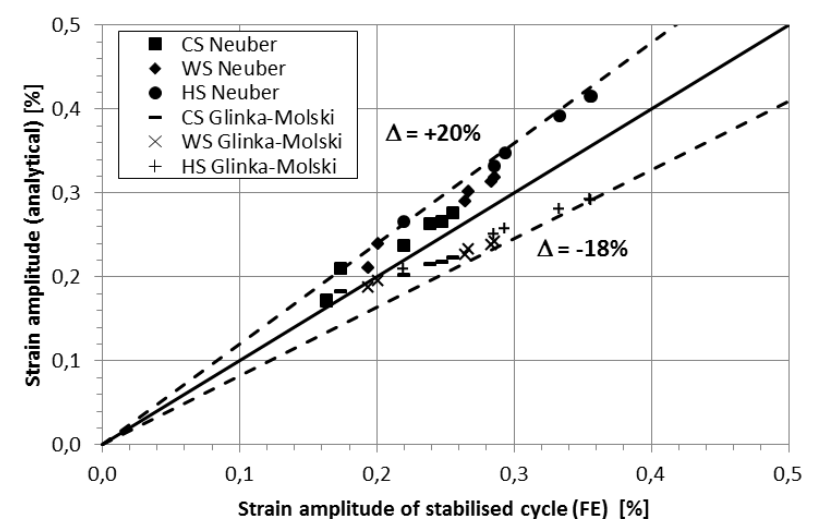

Fig. 11. Strain amplitudes determined with analytical methods and FEA of stabilised cycle

The elastic-plastic hysteresis loops and thermoelastic stress variations were used to determine the strain amplitudes for all grooves and start-up types. Fig. 11 presents the analytically calculated strain amplitudes with the corresponding amplitudes obtained from elastic-plastic material model. The dashed lines represent maximum deviations of each method from the elasticplastic FE predictions. All the grooves with plastic deformation were considered in the analyses and in total 18 points are plotted for each method.

As it is seen in Fig. 11, the Neuber method overpredicts the strain amplitude and the maximum deviation attains $+20 \%$. At the same time, the strain amplitudes obtained from the Glinka-Molski method are below the values computed in elastic-plastic FEA. The maximum error is in this case below $-18 \%$. The average error of strain amplitude estimation calculated for all points in Fig. 11 is $+13 \%$ for the Neuber rule and $-10 \%$ for the Glinka-Molski method.

It can be observed from the figure that the absolute difference between both methods increases with increasing strain amplitudes. The results also confirm a generally observed behaviour that the Neuber method provides an upper bound limit of strain amplitude, while the Glinka-Molski method results in a lower bound limit. From a viewpoint of strain amplitude accuracy both methods are equivalent and can be used for estimating lower and upper bound limits of fatigue life of heat grooves under thermomechanical loading conditions.

\section{FATIGUE LIFE ESTIMATION}

Fatigue life assessment was performed using the strain amplitudes obtained analytically from equation (14) and (15), as well as from the hysteresis loops calculated with the help of the elasticplastic material model described in Section 3. Fig. 12 compares the number of cycles to crack initiation obtained based on the analytically evaluated strain amplitudes with those predicted by the non-linear FE analysis. The numbers of fatigue cycles obtained based on Neuber rule are lower than those resulting from the elastic-plastic material model, while the numbers of cycles 
predicted based on Glinka-Molski method are always higher. The relative errors are comparable for both methods: Neuber rule underpredicts the low-cycle fatigue life maximum by a factor of 3 (life factor $k=1 / 3$ ), while Glinka-Molski method overpredicts the fatigue life by the same factor $(k=3)$. It is also seen from Fig. 12 that deviation in fatigue life decreases with the increasing number of cycles, which is a consequence of the strain amplitude behaviour presented in Fig. 11.

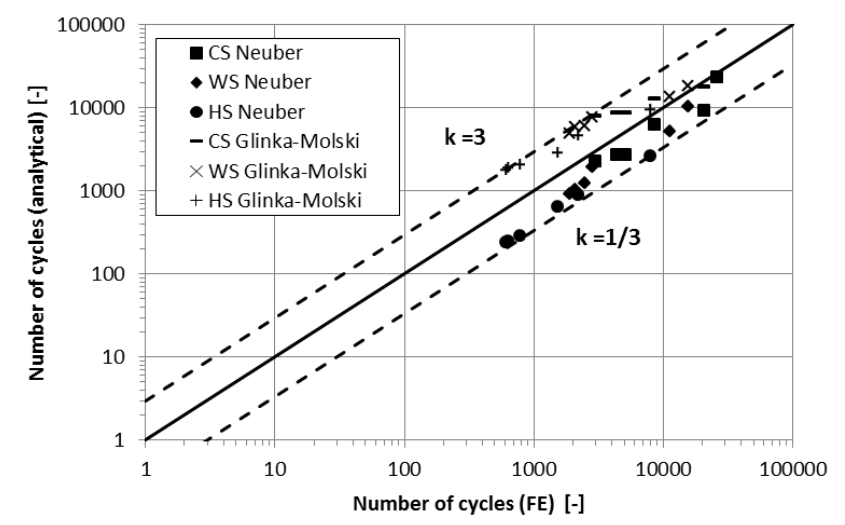

Fig. 12. Number of cycles to crack initiation determined with analytical methods and FEA of stabilised cycle

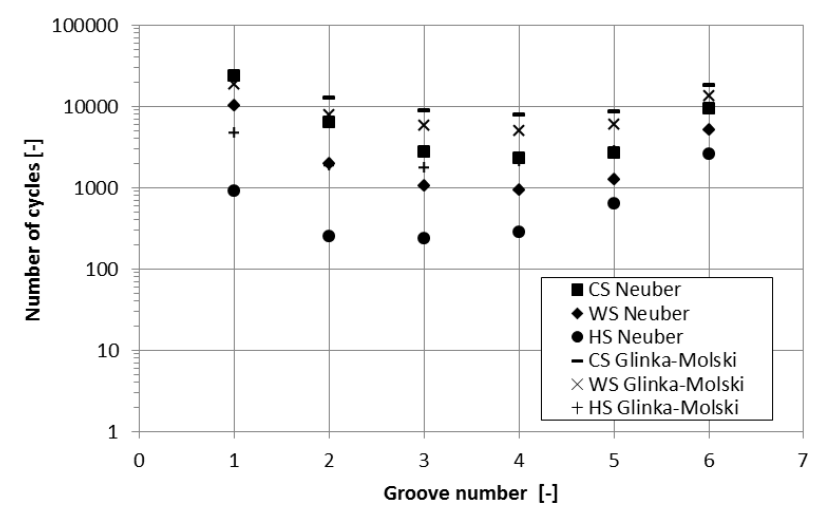

Fig. 13. Distribution of the number of cycles determined using Neuber rule and Glinka-Molski method

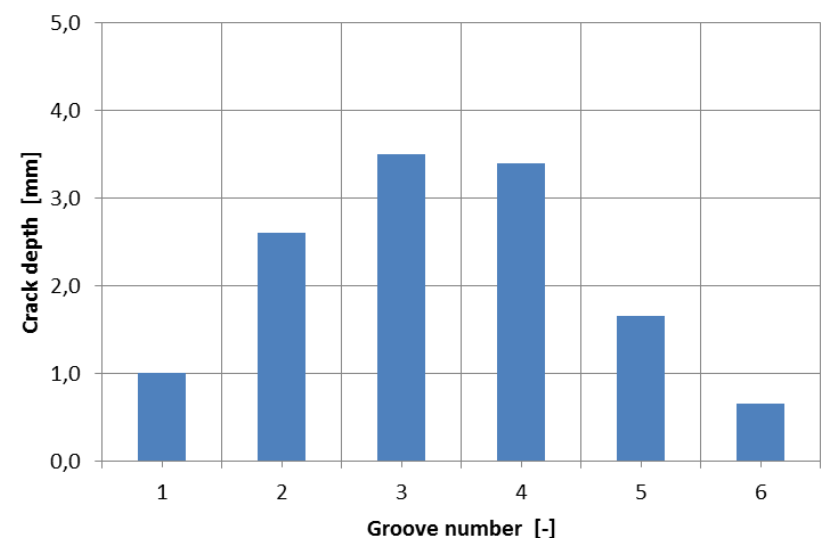

Fig. 14. Crack depths found in 6 heat grooves during the rotor inspection

The observed scatter in the number of cycles results not only from different stresses and strains generated during various startup conditions, but is also a result of different stress and strain maxima occuring at each heat groove during the same start-up.
This variation in peak stresses and strains results in the distribution of the number of cycles shown in Fig. 13. The lowest numbers of cycles were calculated for the middle grooves 3 and 4 at which the largest strain amplitudes were found.

The distribution of the number of cycles to crack initiation shown in Fig. 13 very well correlates with the distribution of fatigue crack length found during a steam turbine rotor inspection, as shown in Fig. 14. The examined rotor was in operation for nearly 300000 hours and accumulated 478 cold and 576 hot starts. The largest cracks of depth exceeding $3 \mathrm{~mm}$ were found in grooves 3 and 4 for which the shortest fatigue lives were predicted both by Neuber rule and Glinka-Molski method.

Tab. 2. LCF damage estimation of heat groove 3

\begin{tabular}{|c|c|c|c|c|c|}
\hline \multirow{2}{*}{ Method } & \multicolumn{2}{|c|}{$\begin{array}{c}\text { Cycles to } \\
\text { cracking [-] }\end{array}$} & \multicolumn{3}{|c|}{ Damage [-] } \\
\cline { 2 - 6 } & $\begin{array}{c}\text { Cold } \\
\text { starts }\end{array}$ & $\begin{array}{l}\text { Warm } \\
\text { starts }\end{array}$ & $\begin{array}{c}\text { Cold } \\
\text { starts }\end{array}$ & $\begin{array}{c}\text { Warm } \\
\text { starts }\end{array}$ & Total \\
\hline Neuber & 2719 & 239 & 0.176 & 2.410 & 2.586 \\
\hline $\begin{array}{c}\text { Glinka- } \\
\text { Molski }\end{array}$ & 8784 & 1757 & 0.054 & 0.328 & 0.382 \\
\hline FEA & 4442 & 611 & 0.108 & 0.943 & 1.050 \\
\hline
\end{tabular}

Both analytical methods of notch stress-strain correction were also used to assess the low-cycle fatigue damage of the rotor at the most critical heat groove 3 where the largest crack of $3.5 \mathrm{~mm}$ depth was found. Fatigue crack initiation life was estimated using the linear damage accumulation model (Seweryn, 1997) which is still widely used in fatigue analysis of components subject to variable loading conditions and recommended to lifetime assessment of steam turbines (Banaszkiewicz, 2015). The total fatigue damage $D_{L C F}$ is calculated from the following equation:

$D_{L C F}=\sum_{\mathrm{i}=1}^{n} \frac{1}{N_{i}}$

where $n$ is the number of cycles accumulated in service and $N_{i}$ is the number of cycles to crack initiation. The number of cycles accumulated in service was split into cold and hot start cycles as only these numbers were available from the turbine operating history. The results of fatigue damage estimation are presented in Table 2, which for comparison purposes also includes the predictions of elastic-plastic material model. The latter model predicts the fatigue damage slightly exceeding 1 , which is above the lower scatter band limit of the linear damage accumulation rule equal 0.75 (Szala et al., 2014). Neuber rule overpredicts the FEA damage by a factor of 2.5, while Glinka-Molski method results in damage being approximately $40 \%$ of that obtained using elastic-plastic FEA. Basing on the above results and the numbers of cycles presented in Fig. 12 it can be concluded that Neuber rule provides a lower bound limit, while Glinka-Molski method provides an upper bound limit of fatigue life of turbine rotors determined by the heat groove damage.

\section{SUMMARY}

The paper presented the analysis of applicability of Neuber and Glinka-Molski methods to strain amplitude evaluation and fatigue life prediction of heat grooves under thermomechanical loads. 
The results of numerical calculations demonstrated a reasonably good agreeement between the strain energy density in the actual elastic-plastic and fictituous elastic state of the rotor heat grooves. With this confirmation, the use of analytical methods of stress-strain correction assuming the equivalence of both energies, was justified.

The elastic-plastic analyses results showed that the plasticity zone at the heat grooves is highly localized and extends from the groove bottom surface towards the rotor axis on a very small depth. Thus, the non-isothermal low-cycle fatigue of the grooves takes place under small-scale yielding conditions.

Comparison of the strain amplitudes predicted by both methods with those obtained from elastic-plastic FEA confirmed the known behaviour of the analytical methods in isothermal conditions showing that Neuber method provides an upper bound limit, while Glinka-Molski method results in a lower bound limit of strain amplitude. In this particular case of circumferential heat grooves, both methods result in similar strain amplitude deviations for stabilised cycles and are suitable to estimating lower and upper bound limits of low-cycle fatigue life of grooved rotors subjected to thermomechanical loads. The analysis of fatigue life performed for real operating conditions of the rotor confirmed the range of accuracy of the analytical methods found in the investigation of the number of cycles to crack initiation.

\section{REFERENCES}

1. Armstrong P., Frederick C. (1966), A mathematical representation of the multiaxial Bauschinger effect, CEGB Report No. RD/B/N 731 .

2. Banaszkiewicz M. (2015), Multilevel approach to lifetime assessment of steam turbines, International Journal of Fatigue, 73, 39-47.

3. Banaszkiewicz M. (2016), Online monitoring and control of thermal stresses in steam turbine rotors, Applied Thermal Engineering, 94, 763-776.

4. Banaszkiewicz M. (2018), The low-cycle fatigue life assessment method for online monitoring of steam turbine rotors, International Journal of Fatigue, 113, 311-323.

5. Bednarski T. (1995), Mechanics of plastic flow, PWN, Warsaw (in Polish).

6. Buczyński A., Glinka G. (1997), Elastic-plastic stress-strain analysis of notches under non-proportional loading, 5th International Conference on Biaxial/Multiaxial Fatigue and Fracture, Cracow.

7. Buczyński A., Glinka G. (2001), An analysis of elasto-plastic strains and stresses in notched bodies subjected to cyclic non-proportional loading paths, 6th International Conference on Biaxial/Multiaxial Fatigue and Fracture, Lisbon.

8. Celins C., Pinto G.R.S., Teixeira T., Xavier E. (2017), A steam turbine dynamic model for full scope power plant simulations, Applied Thermal Engineering, 120, 593-602.

9. Chaboche J.L. (1986), Time-independent constitutive theories for cyclic plasticity, International Journal of Plasticity, 2(2), 149-188.

10. Garud Y.S. (1981), A new approach to the evaluation of fatigue under multiaxial loadings, Journal of Engineering Materials and Technology -Transactions ASME, 103(2), 118-125.

11. Gehlot S., Mahadevan P., Kannusamy R. (2012), Analytical correction of nonlinear thermal stresses under thermo-mechanical cyclic loadings, Proceedings of ASME Turbo Expo, Copenhagen.

12. Gordon A.P., Williams E.P., Schulist M. (2008), Applicability of Neuber's rule to thermomechanical fatigue, Proceedings of ASME Turbo Expo, Berlin.

13. Guo W., Wang C.H., Rose L.R.F. (1998), Elasto-plastic analysis of notch-tip fields in strain hardening materials, Aeronautical and Maritime Research Laboratory Report, DSTO-RR-0137, 1-36.
14. Harkegard G., Mann T. (2003), Neuber prediction of elastic-plastic strain concentration in notched tensile specimens under large-scale yielding, Journal of Strain Analysis, 38, 79-94.

15. Hoffman M., Seeger T. (1985), A generalized method for estimating multiaxial elastic-plastic notch stresses and strains - Part I and II, ASME Journal of Engineering Materials and Technology, 107, $250-260$.

16. Ince A. (2016), Numerical validation of computational stress and strain analysis model for notched components subject to nonproportional loadings, Theoretical and Applied Fracture Mechanics, 84, 26-37.

17. Ince A. (2017), A Computational Multiaxial Model for Stress Strain Analysis of Ground Vehicle Notched Components, SAE International Journal of Engines, 10(2), 316-322.

18. Ince A., Bang D. (2017), Deviationic Neuber method for stress and strain analysis at notches under multiaxial loadings, International Journal of Fatique, 102, 229-240.

19. Ince A., Glinka G. (2013), A numerical method for elasto-plastic notch-root stress-strain analysis, Journal of Strain Analysis, 48(4), 229-244.

20. Ince A., Glinka G. (2016), Innovative computational modeling of multiaxial fatigue analysis for notched components, International Journal of Fatigue, 82, 134-145.

21. Ince A., Glinka G., Buczyński A. (2014), Computational modeling of multiaxial elasto-plastic stress-strain response for notched components under non-proportional loading, International Journal of Fatigue, 62, 42-52.

22. Koneko Y., Kanki H., Kawashita R. (2017), Steam turbine rotor design and rotor dynamics analysis [in book:] Advances in steam turbines for modern power plant, 127-152, Woodhead Publishing.

23. Kosman W., Roskosz M., Nawrat K. (2009), Thermal elongations in steam turbines with welded rotors made of advanced materials at supercritical steam parameters, Applied Thermal Engineering, 29 (16), 3386-3393.

24. Lemaitre J., Desmorat R. (2005), Engineering damage mechanics, Springer-Verlag, Berlin Heidelberg.

25. Moftakhar A., Buczyński A., Glinka G. (1995), Calculation of elasto-plastic strains and stresses in notches under multiaxial loading, International Journal of Fracture, 70, 357-373.

26. Molski K., Glinka G. (1981), A method of elastic-plastic stress and strain calculation at a notch root, Material Science and Engineering, $50,93-100$.

27. Mróz Z. (1967), On the description of anizotropic work hardening, Journal of the Mechanicsand Physics of Solids, 15, 163-175.

28. Neuber H. (1961), Theory of stress concentration for shear-strained prismatical bodies with arbitrary non-linear stress-strain law, ASME Journal of Applied Mechanics, 28, 544-550.

29. Seweryn A. (1997), Damage accumulation and cracking of elements under complex states of loading, Scientific Transactions of Bialystok University of Technology, 42.

30. Shin C.S., Man K.C., Wang C.M. (1994), A practical method to estimate the stress concentration of notches, International Journal of Fatigue, 16, 242-256.

31. Szala J., Ligaj B., Szala G. (2014), Sources of differences in calculations and experimental test results of fatigue life of structural elements, Scientific Journal of Silesian University of Technology. Series Transport, 83, 271-277.

32. Tricoteaux A., Fardoun F., Degallaix S., Sauvage F. (2007), Fatique crack initiation life prediction in high strength structural steel welded joints, Fatique \& Fracture of Engineering Materials \& Structures, 18(2), 189-200.

33. Viswanathan R. (1989), Damage mechanisms and life assessment of high-temperature components, ASM International, Metals Park, Ohio.

34. Zeng Z., Fatemi A. (2001), Elasto-plastic stress and strain behaviour at notch roots under monotonic and cyclic loadings, Journal of Strain Analysis, 36, 287-300. 